\title{
Rate effect in inclined fibre pull-out for smooth and hooked-end fibres: a numerical study
}

\author{
Elisa Poveda $(\mathbb{D})$ Rena C. Yu(i) • \\ Manuel Tarifa $₫$ - Gonzalo Ruiz $\bullet$ \\ Vítor M. C. F. Cunha $\mathbb{D}$. \\ Joaquim A. O. Barros $\mathbb{D}$
}

Received: 11 August 2019 / Accepted: 19 November 2019 / Published online: 3 December 2019

(C) Springer Nature B.V. 2019

\begin{abstract}
Based on a numerical model to simulate the static behaviour of a smooth fibre extracted from a cementitious matrix, a rate dependent friction law, widely used in earthquake engineering for steady-state slip phenomena, is proposed to capture the rate effect observed in dynamic pull-out tests for both smooth and hooked-end fibres. After calibrating the friction coefficients with the experimental results of smooth fibres, the model is subsequently applied to predict the pullout behaviour of both smooth and hooked-end fibres at different inclination angles $\left(0^{\circ}, 30^{\circ}\right.$ and $\left.60^{\circ}\right)$ loaded at three different velocities $(0.01,0.1$ and $1 \mathrm{~mm} / \mathrm{s})$. The global tendency of all the pull-out curves was captured, fibre's cross sectional deformations were also reproduced remarkably well. Moreover, the developed model helps to cast light on the different mechanisms related to the pull-out process.
\end{abstract}

E. Poveda $(\varangle) \cdot$ R. C. Yu · G. Ruiz

E.T.S. de Ingenieros de Caminos, C. y P., UCLM, Avda.

Camilo José Cela s/n, 13071 Ciudad Real, Spain

e-mail: elisa.poveda@uclm.es

M. Tarifa

E.T.S.I. Aeronáutica y del Espacio, Universidad Politécnica de Madrid, Pza. del Cardenal Cisneros 3, 28040 Madrid, Spain

V. M. C. F. Cunha · J. A. O. Barros

Department of Civil Engineering, ISISE, Institute of Science and Innovation for Bio-Sustainability (IB-S), University of Minho, 4800-058 Guimarães, Portugal
Keywords Rate-dependent friction - Smooth and hooked-end fibres $\cdot$ SFRC $\cdot$ Inclination angle $\cdot$ Pull-out rate

\section{Introduction}

Steel fibre reinforced concrete (SFRC) is a composite material in which steel fibres are randomly oriented and distributed in a concrete matrix. The benefits of fibre addition in energy absorption and toughness, particularly under dynamic loading conditions, are demonstrated in the scientific bibliography (ACI Committee 544 2002; Soufeiani et al. 2016; Yu et al. 2016; Zhang et al. 2017; Poveda et al. 2017; Blason et al. 2019; Ruiz et al. 2018, 2019). This makes SFRC a suitable material for civil engineering structures, especially when they are subjected to dynamic conditions such as seismic loads, impact or explosions. Consequently, the study of the behaviour of SFRC at different loading rates is crucial for the maintenance and the structural integrity of these structures.

It is well-known that structural fibres improve the performance of cementitious composites by acting as bridging ligaments for cracks. Such bridging capacity is primarily studied through single-fibre pull-out tests. The relationship between the pull-out force versus loaded end extracted length is characteristic of the fibre-matrix interface. Such a relation varies significantly with the fibre inclination angle (Leung and Shapiro 1999; Cunha 2010), fibre type (Xu et al. 2016), 
the fibre extracting velocity (Gokoz and Naaman 1981; Banthia and Trottier 1991; Bindiganavile and Banthia 2005; Kim et al. 2008; Abu-Lebdeh et al. 2010; Xu et al. 2016) and the matrix strength (Banthia and Trottier 1991; Abu-Lebdeh et al. 2010). Although the displacement rate sensitivity of the fibre pull-out behaviour has been experimentally explored (Gokoz and Naaman 1981; Banthia and Trottier 1991; Kim et al. 2008; AbuLebdeh et al. 2010; Xu et al. 2016), models capable of explaining the combined effect of fibre inclination and pull-out rate (Xu et al. 2016; Bindiganavile and Banthia 2005; Bhutta et al. 2018) are still lacking.

Static pull-out behaviour has been simulated through analytical (Ruiz et al. 1998, 1999; Ruiz 2001; Nonato Da Silva et al. 2019) or numerical models (Hajsadeghi et al. 2018). Attempts have also been made to predict the time-dependent pull-out behaviour of smooth and hooked-end fibres (Xu et al. 2016; Nieuwoudt and Boshoff 2017). In the latter case, the mechanical anchorage at the embedded end of the fibre plays an important role in determining the rate sensitivity of the mobilised pull-out load. In fact, Nieuwoudt and Boshoff (2017), against other authors, affirmed that the contribution of the anchor makes the hooked-end fibre insensitive to rate at the peak load. This anchorage can be represented either as plastic hinges (Alwan et al. 1999) or as a nonlinear virtual spring (Sujivorakul et al. 2000; Cunha et al. 2010). Nonato Da Silva et al. (2019), Cunha (2010) and Sujivorakul et al. (2000) derived models to predict the pull-out force-slip relationship for hooked-end steel fibres. However, an approach to model the single fibre pull-out behaviour at different inclinations subjected to different displacement rates is still lacking, not to mention when hookedend fibres are concerned.

Nieuwoudt and Boshoff (2017) extended the analytic model by Cunha (2010) to predict the dynamic pull-out behaviour of hooked-end steel fibres. Based on a Kelvin-Voight model, they simulated the mechanical and rheological mechanisms through springs and dashpots. The mechanical contribution of the anchorage was analytically obtained by subtracting the experimental pull-out curves of smooth fibres from those of hookedend fibres. With this model, they drew attention to the importance of predicting the time-dependent behaviour at a microscopic scale and the influence of parameters such as fibre inclination angle.

Tai and El-Tawil (2017) proposed a simple analytical model for inclined smooth fibres that fit their experi- mental results. They also fitted three different analytical expressions for the experimental results obtained at the three displacement rates, without delving into the influence of the pull-out rate. This model is based on the snubbing effect (Li et al. 1990) and matrix spalling, both important mechanisms when inclined fibres are extracted with a certain velocity (Lee et al. 2010).

The fact that friction is rate and state dependent is well-known in earthquake engineering. However, it has not been taken into consideration so far for dynamic fibre pull-out behaviours. In the current work, the fibrematrix interface is assimilated to an earthquake fault. Consequently, the dynamic pull-out process at a fixed rate is analogous to that of a slipping fault under steady state conditions. In other words, the experimentally observed rate effect on the pull-out curves is attributed to the rate-dependent friction law at the interface. The numerical model by Zhang and $\mathrm{Yu}$ (2016) is taken as a starting point to incorporate such rate-dependent friction laws. Since the concrete matrix, the steel fibre and the interface in-between are explicitly represented, the modelling of hooked-end fibres (inclined or not) is only geometrically more complex, the numerical methodology is exactly the same as that of smooth fibres. Cohesive elements endorsed with mixed-mode fracture capacities are implemented to simulate the bondslip behaviour at the interface. Contact elements with Coulomb's friction are overlapped with the cohesive ones to capture the frictional contact. The friction coefficients follow a rate dependent friction law at steady state conditions (Marone 1998; Rice et al. 2001).

Hereinafter, the paper is organised as follows. A brief description of the experimental programme is presented in Sect. 2. The mechanism behind static pull-out phenomenon and the slip rate dependent friction law is introduced in Sect. 3. The corresponding numerical methodology is summarised in Sect. 4. Validations against experimental results, revelation of the observed phenomena involved in a pull-out process are given in Sect. 5. Finally, relevant conclusions are drawn in Sect. 6.

\section{Experimental programme}

The main objective of the experimental programme was to determine the mechanical response of fibres at different pull-out rates and inclinations by analysing the load-extracted length curves at the load application 


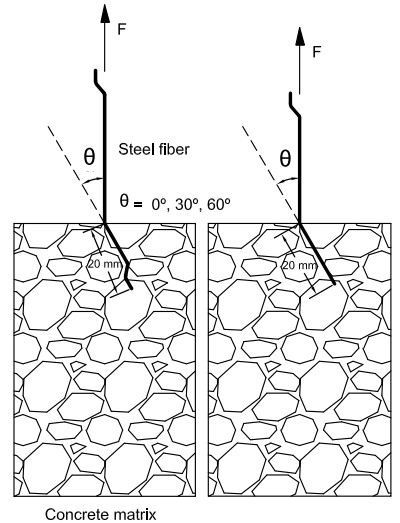

(a)

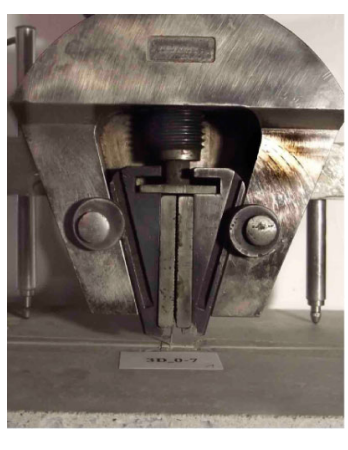

(c)
Fig. 1 Configuration of the single fibre pull-out test: a hookedend fibre, $\mathbf{b}$ smooth fibre and $\mathbf{c}$ general view of the adopted test set-up

point. Single fibre pull-out tests were carried out on smooth and hooked-end steel fibres in the Laboratory of Structures, in the University of Minho. The hookedend fibres were supplied from BEKAERT company, meanwhile the smooth ones were obtained by cutting the hook off. Smooth and hooked-end fibres of $60 \mathrm{~mm}$ in length, $0.75 \mathrm{~mm}$ in diameter were embedded in a self-compacting concrete with a length of $20 \mathrm{~mm}$, see Fig. 1. The concrete matrix was made of granite coarse aggregates with a maximum size of $20 \mathrm{~mm}$, cement CEM I $42.5 \mathrm{R}$, limestone filler and super-plasticiser, with a mix proportioning of 1:0.69:2.18:1.67:0.17:0.017 (cement:filler:sand:coarse aggregate:water:super-plasticiser).

Tests were carried out at three displacement velocities: $0.01,0.1$ and $1 \mathrm{~mm} / \mathrm{s}$, and at three different embedded angles: $0^{\circ}, 30^{\circ}$ and $60^{\circ}$ with respect to the loading direction. The free ends of the fibre were held by a grip (see Fig. 1c), further details of the experimental set-up can be found elsewhere (Tarifa et al. 2019). Note that the tests regarding the slowest rate $(0.01 \mathrm{~mm} / \mathrm{s})$ were obtained by Cunha (2010). Material parameters, such us, density, $\rho$, Poisson's ratio, $v$, elastic modulus, $E$, tensile strength, $f_{t}$, and compressive strength, $f_{c}$, are given in Table 1. Cubic specimens of $150 \mathrm{~mm}$ in edge length were made for standard characterisation tests to measure the compressive strength. The fibre tensile strength was obtained by means of six tensile tests in a closed-loop displacement control. The values for the other parameters are estimated.
Table 1 Material parameters for concrete matrix and steel fibre

\begin{tabular}{llllll}
\hline & $\rho\left(\mathrm{kg} / \mathrm{m}^{3}\right)$ & $E(\mathrm{GPa})$ & $v-$ & $f_{c}(\mathrm{MPa})$ & $f_{t}(\mathrm{MPa})$ \\
\hline Matrix & 2100 & 35 & 0.20 & 85.9 & 4.8 \\
Fibre & 7800 & 210 & 0.33 & - & 1313 \\
\hline
\end{tabular}

\section{Pull-out behaviour of steel fibres: the mechanisms involved}

In this section, the mechanisms behind fibre pull-out are explained. The gradual interfacial degradation is described as the combination of bond-slip deterioration and frictional contact. For dynamic pull-out, a ratedependent friction law is proposed to capture the rate effect. The matrix spalling is dealt with in a simplified way to save computation cost.

\subsection{Interface bond characterisation}

The relationship between the shear stress and the slip at the fibre-matrix interface is considered as a constitutive property. Its characterisation is essential for the prediction of the mechanical and fracture properties of fibre-reinforced concrete. However, it is not an easy task due to the complex nature of the bond (Naaman and Najm 1991).

The physicochemical bond characterisation (Nammur and Naaman 1989; Naaman and Najm 1991; Abrishambaf et al. 2017) comprises not only the debonding of the surround interface but also the frictional slip of the fibre. Figure 2a represents the behaviour of a single smooth fibre (Cunha 2010), i.e. the pull-out load vs. extracted-length $(F-u)$ curve. In a smooth steel fibre, three different parts can be identified. Firstly, the pullout load increases with the extracted length, this is the elastic bond and the micro-cracking corresponding to the initiation of the debonding process. After the maximum load is reached, the load decreases as the fibre continues being extracted, unstable interfacial crack growth takes place on the post-peak behaviour, i.e. the interfacial crack grows even though the pullout load decreases, and full debonding is produced (branch BC). Subsequently, the fibre pull-out occurs only under frictional slip (branch CD), in this part of the post-peak branch, the load also decreases with increase of the extracted length, since both the available frictional area and the channel surface rough- 


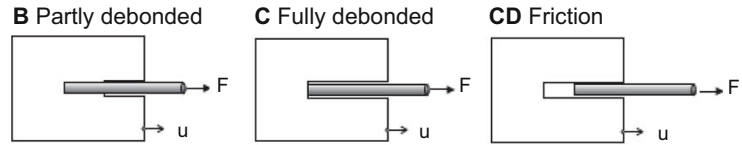

$\mathbf{F}$

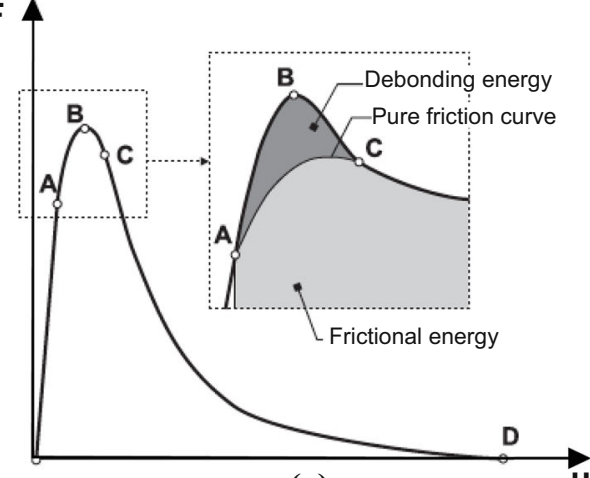

$\tau$

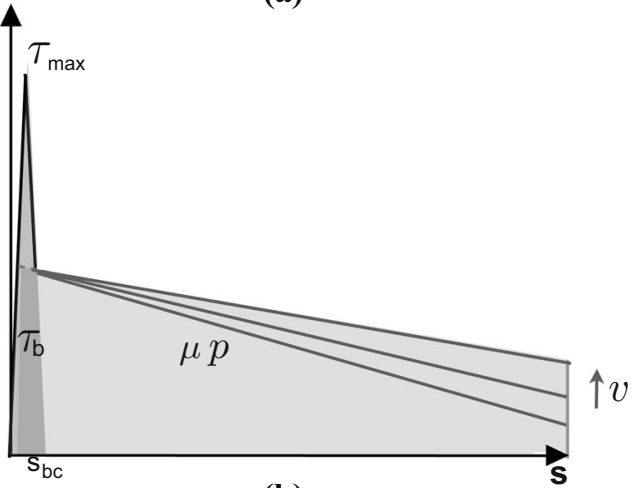

(b)

Fig. 2 a Pull-out relationship for smooth fibre and $\mathbf{b}$ bond-slip law at the interface (dependent on the slip rate, $v$ )

ness decrease. With regard to hooked-end fibres, the mechanisms involved are similar to those previously reported (Markovic 2006; Abdallah et al. 2018), except for the contribution of mechanical anchorage (Cunha 2010; Alwan et al. 1999), which is naturally considered when the fibre geometry is explicitly represented in the numerical simulations.

As previously seen, the mechanism of the load transference at the interface are done first by adhesion bond stress and then by frictional ones. Consequently, a generic constitutive law with two components can be proposed to reflect the gradual deterioration at the interface. The first component, $\tau_{b}(s)$, provides the interfacial bond relation due to physical and chemical cohesion. Owing to its cohesive origin, it can be modelled by cohesive elements with mode II fracture capacity. It decreases until a critical slip displacement is reached. The second component of the bond constitutive law is composed, due to the frictional contact, by the frictional resistance, which resists the motion between the fibre and the matrix. This term illustrates the shear stress due to dry friction and it is activated in the presence of normal contact pressure.

For the purpose of numerical simulation, in order to activate friction, an inclination angle of $1^{\circ}$ is employed to simulate the case of zero-degree smooth fibre pullout. By contrast, in the hooked-end fibre this term acts even with zero embedded angle due to the fact that during the plastic deformation of the hook it exerts compression in the concrete matrix. As it will be explained in the next subsection, the influence of the displacement rate is exclusively represented in the friction coefficient.

The shear stress at the interface can be decomposed as follows

$\tau(s, v)=\tau_{b}(s)+\mu(v) p$,

where $\tau_{b}(s)$ is the interfacial bond as a function of the local slip displacement, $s$, while the second term is due to the frictional contact. The angle $\theta$ is the one between the longitudinal direction of the embedded fibre and the load direction, $v$ is the slip rate, $\mu$ is the Coulomb's friction coefficient and $p$ is the contact pressure. It should be noted that $p$ is automatically obtained in the calculations, whereas $\mu(v)$ needs to be defined as part of the constitutive relation.

For $\tau_{b}(s)$, a linear-decreasing bond-slip relation is assumed before a critical slip displacement, $s_{b c}$, is reached. After this value the bond is completely exhausted, and only the friction term is left, i.e.

$\tau_{b}(s)=\tau_{\max }\left(1-\frac{s}{s_{b c}}\right), 0 \leq s \leq s_{b c}$,

where $\tau_{\max }$ is the maximum shear stress resisted at the interface.

\subsection{Rate-dependent friction}

In earthquake engineering, it is well-known that the static frictional strength varies with loading rate, and the mechanism of frictional sliding is a function of time and slip (Marone 1998). Such a phenomenon is often described by rate and state dependent friction laws. Rice et al. (2001) affirmed that the 
Table 2 Friction coefficient, $\mu$, calculated according to Eq. (3) for fibres (smooth or hooked-end) at different pull-out rates

\begin{tabular}{lll}
\hline $0.01(\mathrm{~mm} / \mathrm{s})$ & $0.1(\mathrm{~mm} / \mathrm{s})$ & $1.0(\mathrm{~mm} / \mathrm{s})$ \\
\hline 0.30 & 0.53 & 0.75 \\
\hline
\end{tabular}

variation of friction strength with slip rate generally involves a positive increase proportionally to $\ln (v)$. For a steady-state slip, the friction coefficient is related to the slip rate, $v$, as follows

$\mu(v)=\mu_{0}+c \ln \left(\frac{v}{v_{0}}\right)$

where $\mu_{0}$ is the quasi-static friction coefficient, $v_{0}$ is the quasi-static slip rate, assumed as $0.01 \mathrm{~mm} / \mathrm{s}$ herein, whereas $c$ is a fitted parameter.

In the current work, Eq. (3) was used for the friction between steel fibre and concrete matrix to model the rate effect observed in the pull-out tests of inclined fibres $\left(0^{\circ}, 30^{\circ}\right.$ and $60^{\circ}$ with respect to the load direction), carried out at three displacement rates $(0.01,0.1$ and $1 \mathrm{~mm} / \mathrm{s}$ ). The parameters $\mu_{0}$ and $c$ were fitted as 0.30 and 0.1 using the experimental results for smooth fibres at $0^{\circ}$ carried out at 0.01 and $0.1 \mathrm{~mm} / \mathrm{s}$, respectively.

It should be pointed out that, even though the static friction coefficient between concrete and steel was estimated by Rabbat and Russell (1985) to be between 0.57 and 0.70 , sudden alteration of normal stress along the interface may cause it to drop at the order of $1 / 3$ (Rice et al. 2001). Consequently, 0.30 was assumed a reasonable value for $\mu_{0}$. The friction for the rest of the displacement rates obtained according to Eq. (3) are given in Table 2.

\subsection{Matrix spalling}

Matrix spalling often occurs during the pull-out of inclined fibres. For instance, the spalling produced by smooth and hooked-end fibres inclined at $0^{\circ}, 30^{\circ}$ and $60^{\circ}$ are given in Fig. 3. It can be noted that the spalled area grows with the inclination angle. This is also in agreement with the findings of Laranjeira et al. (2010a) and Li et al. (1990). For simplification, the spalled part can be removed in numerical simulations, once the tensile stress exceeds the matrix tensile strength (Laran-
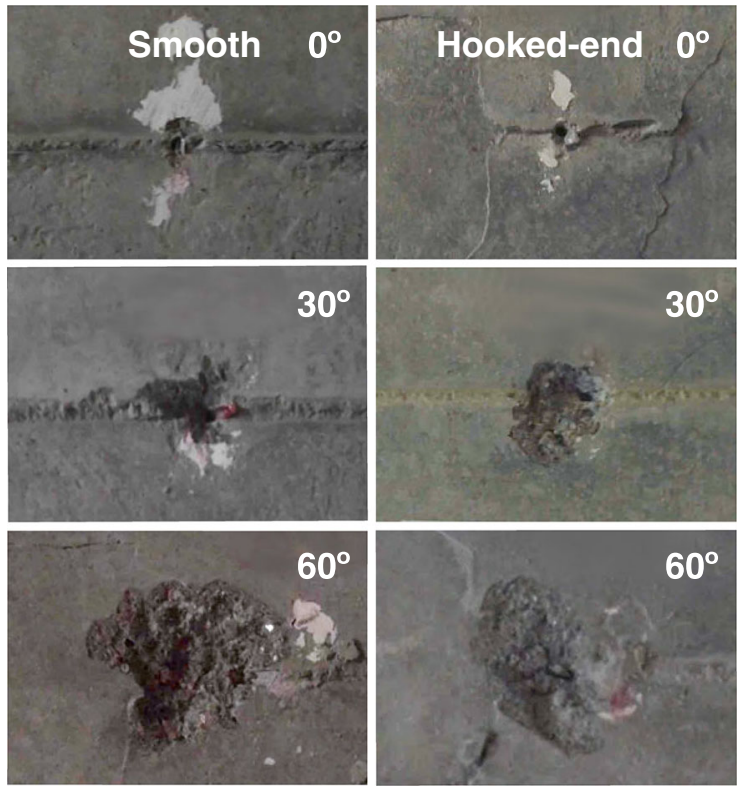

Fig. 3 Matrix spalling observed after the pulling out of smooth (left) and hooked-end fibres (right) inclined at $0^{\circ}, 30^{\circ}$ and $60^{\circ}$, respectively

jeira et al. 2010a). The length of the spalled matrix along the fibre direction is denoted as the spalling length, $L_{s p}$. According to Laranjeira et al. (2010a), it can be estimated as follows,

$a L_{s p}^{2}+b L_{s p}+c=0$,

where

$a=\frac{\sqrt{2}}{\sin \theta}+\frac{\cos \theta}{\sin ^{2} \theta}, b=\frac{d_{f}}{\sin \theta}, c=-\frac{P_{\max } \sin \theta}{f_{t}}$,

being $d_{f}$ the fibre diameter, $\theta$ the inclination angle, $P_{\text {max }}$ the peak pull-out load of an aligned fibre, whereas $f_{t}$ is the tensile strength of the matrix.

As mentioned by Zhang and Yu (2016), Eq. (4) is taken as a simplified approach to calculate the size of the matrix wedge, which is to be spalled off. This wedge is attached to the rest of the matrix through cohesive elements. Probing simulations are conducted to resolve the precise load step at which the matrix wedge should be deactivated. It should be pointed out that such a treatment is only to save computational time since the first principal stresses within the matrix will be checked 


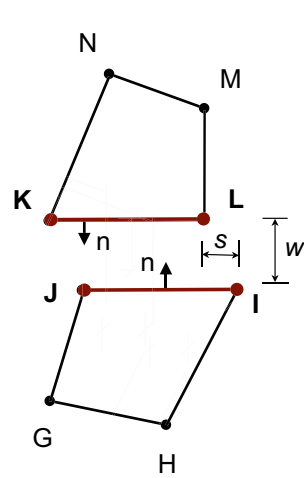

(a)

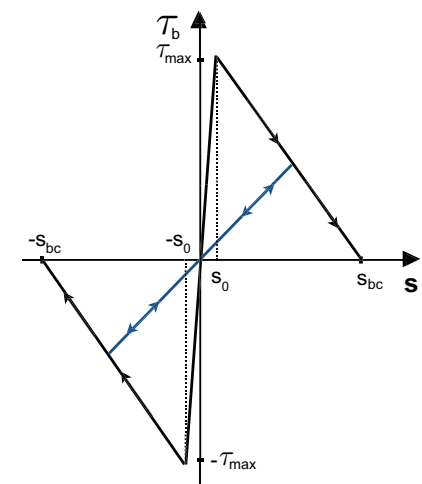

(b)
Fig. 4 a Interface elements I-J and K-L between two four-node solid elements G-H-I-J and K-L-M-N, being $s$ and $w$ the tangential and normal displacement jumps, and $n$ the normal direction of the two line segments; $\mathbf{b}$ the interfacial bond-slip law (shown for a linear-decreasing case)

and the spalled length will be adjusted if necessary. This avoids the overestimation of the global stiffness due to artificial matrix stiffening.

\section{Numerical simulations}

A two-dimensional model explicitly representing the matrix, the embedded fibre and the interface has been developed. Both the fibre and the matrix are represented with four-node two-dimensional solid elements (K-L$\mathrm{M}-\mathrm{N}$ and G-H-I-J), whereas the interface is discretised into pairs of two-node line segments (I-J and K-L), see Fig. 4a. The constitutive behaviour of the interface is governed by a bond-slip law, as shown in Fig. 4b. The initial ascending part aims to eliminate the numerical instability, which can be caused by near-zero slip displacements. Consequently, the zero-damage is set for a small slip displacement, $s_{0}$, when the bond strength, $\tau_{\text {max }}$, is attained; whereas the interface is completely damaged when the slip displacement exceeds a critical value, $s_{b c}$. After that, only frictional forces exist at the interface. For friction, a pair of contact-target elements (I-J and K-L) is superposed at the same nodes of the interface elements.

The numerical model is implemented in ANSYS (2009) through APDL, a script language to automate common tasks and build sophisticated models in terms of parametric variables. Regarding the constitutive laws, linear elasticity until fracture for the matrix and

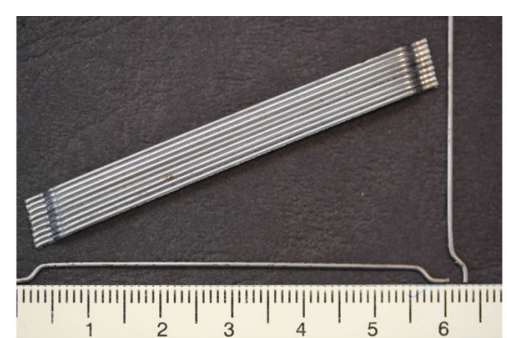

(a)

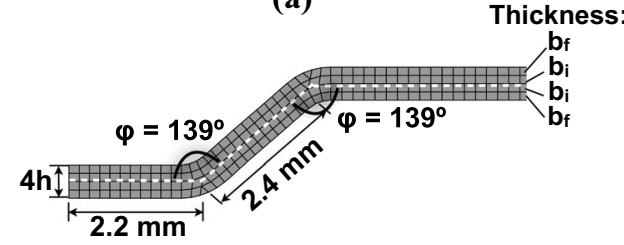

(b)

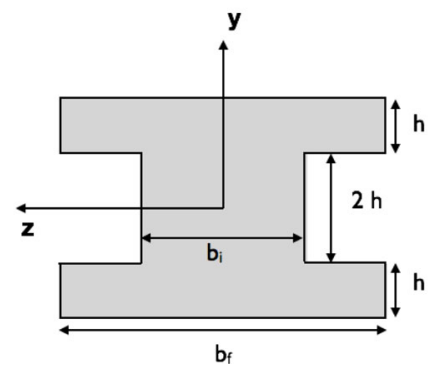

(c)

Fig. 5 a Hooked-end fibres, $\mathbf{b}$ geometric parameters of the hook and $\mathbf{c}$ modelled fibre cross-section

bilinear plasticity with isotropic hardening for the steel fibre are assumed.

\subsection{Geometry and boundary conditions}

The hooked-end fibre and the detailed geometry of the hook are given in Fig. 5. It bears emphasis that the smooth fibres were obtained by cutting off the hook of the original fibre. This guarantees that the same crosssectional geometry and material properties were maintained for both smooth and hooked-end fibres.

Within a two-dimensional plain stress framework, the modelled contact area along the embedded fibre length, $L_{f}$, the moment of inertia and area of the fibre cross-section need to concur with their original counterparts. For this purpose, the fibre is represented with a cross section depicted in Fig. 5c. The outer thickness $b_{f}$, the inner thickness $b_{i}$ as well as the height $4 h$ calculated according to Eqs. (6-8) are of 1.178, 0.411 and $0.556 \mathrm{~mm}$, respectively. 
Fig. 6 In-plane dimensions and boundary conditions (shown only for smooth fibres) for the numerical simulations of the pull-out tests, with a fibre inclination angle of $0^{\circ}, 30^{\circ}$ and $60^{\circ}$, respectively
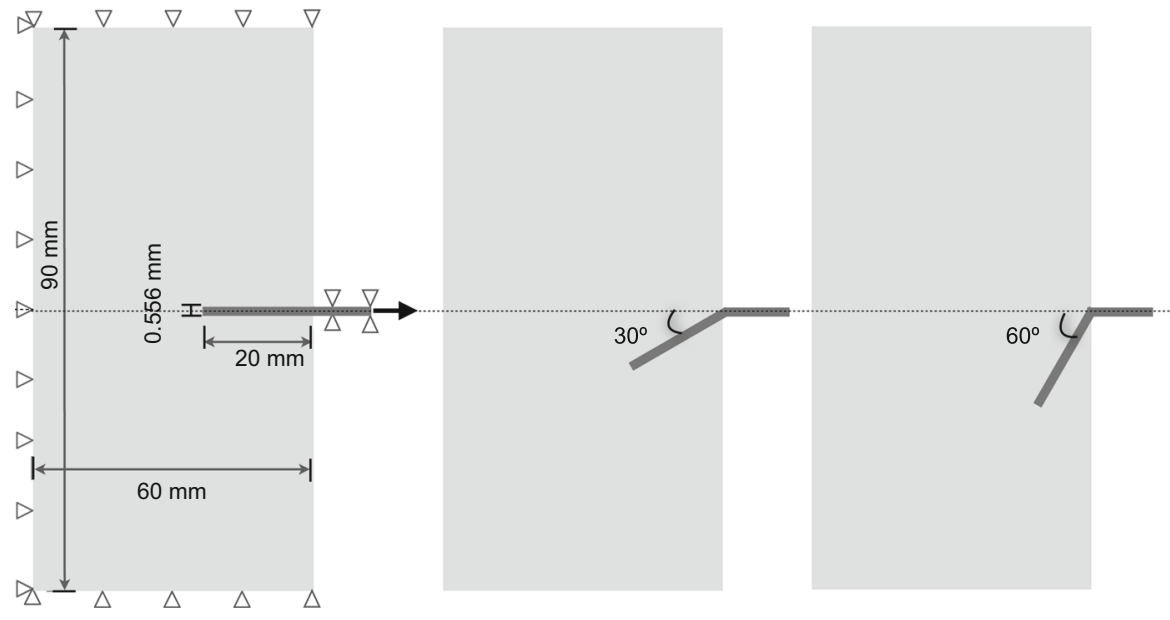

$2 L_{f} b_{f}=\pi d_{f} L_{f}$

$\frac{b_{i}(2 h)^{3}}{12}+2 b_{f} h\left(\frac{3 h}{2}\right)^{2}+2 \frac{b_{f} h^{3}}{12}=\frac{\pi d_{f}^{4}}{64}$

$2 b_{i} h+b_{f} 2 h=\frac{\pi d_{f}^{2}}{4}$.

Finally, the in-plane dimensions and boundary conditions to simulate the pull-out tests, are schematically illustrated in Fig. 6 for the smooth fibres embedded at three different inclination angles. Vertical displacements are prevented on the top and bottom sides, whereas horizontal movements are restrained on the left side of the concrete matrix. The movement of the fibre protruding end is impeded in the vertical direction to simulate the machine grip. Note that the same boundary conditions are imposed for inclined fibres, except for $60^{\circ}$ hooked-end fibres. To allow fibre straightening during matrix spalling for hooked-end fibre at $60^{\circ}$, less restriction (i.e. $2 / 3$ of the fibre protruding end) was imposed on the protruding end of the fibre. The load is applied at the exit point of the fibre, as an imposed displacement.

\subsection{Calibration of the interface parameters}

If a uniform distribution of the bond stress along the embedded length, $L_{e}$, is assumed, the maximum pullout load is related with the bond strength $\tau_{\max }$ as follows

$$
P_{\max }=\pi d_{f} L_{e} \tau_{\max } .
$$

Meanwhile, the value for $P_{\max }$ can be determined from the pull-out response of aligned fibre experimentally obtained at $0.01 \mathrm{~mm} / \mathrm{s}$ (which is considered quasistatic). From the averaged results of two individual fibre pull-out tests for $P_{\max }$ (Cunha 2010), see Fig. 7, $\tau_{\max }$ is calculated as $1.7 \mathrm{MPa}$. The critical slip for interfacial bond, $s_{b c}, 0.3 \mathrm{~mm}$, was obtained by fitting the first decaying branch of the experimental pull-out response (Fig. 7). This value also coincides with that of Zhang and $\mathrm{Yu}$ (2016) for the same parameter.

The static friction coefficient is determined by fitting for the case of smooth fibres at $0^{\circ}$, so that the second branch of the numerical pull-out response should fall within the experimental range as depicted in Fig. 7.

\subsection{Mesh sensitivity}

The mesh size has been carefully selected to reach a compromise between the computational cost and reasonable convergency. The mesh sensitivity in the transverse direction of the fibre is rather small (Zhang and Yu 2016). Nevertheless, the convergency is improved with the mesh refinement.

By contrast, the refinement along the fibre's longitudinal direction has a more pronounced influence. The convergency issue is more critical for the pull-out of inclined hooked-end fibres. A mesh sensitivity analysis was conducted for the hooked-end fibre at $0^{\circ}$ at the lowest displacement rate. In Fig. 8, three levels of mesh refinement, with element size of $0.2 \mathrm{~mm}, 0.13 \mathrm{~mm}$ and $0.1 \mathrm{~mm}$, correspond to 100 divisions, 150 divisions and 200 divisions along embedded fibre. The correspond- 


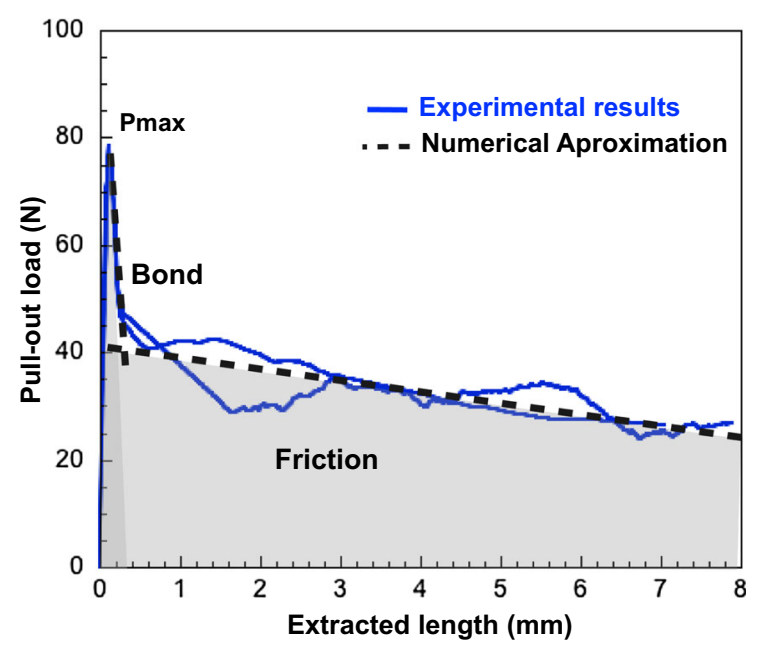

Fig. 7 Experimental range (light blue lines) for pull-out curves for aligned fibre at $0.01 \mathrm{~mm} / \mathrm{s}$ (Cunha 2010) and its bi-linear approximation (black dotted line). $P_{\max }$ is the peak load

ing pull-out load versus the extracted length curves are depicted in Fig. 8 contrasted with the experimental envelope curves. In the case of the coarsest mesh (100 divisions), the curve is already rather close to the experimental envelope. However, manifest oscillations are observed. As the mesh gets finer, the curve tends to be smoother and the convergency is easily reached. Meanwhile, the computational time is significantly increased. No significant differences can be perceived in the peak load for the three levels of mesh refinements, nor in the descending part of the curve. In particular, the responses of the two finer meshes practically coincide. Therefore, except for some particular cases, the mesh size of $0.2 \mathrm{~mm}$ is adopted for further studies.

\section{Validation and discussion}

In this section, the entire numerical pull-out load versus extracted length curves are compared with those obtained experimentally. In addition, the deformed fibre is also contrasted with the experimental one. Moreover, the fibre and matrix stress fields are presented and discussed in order to better illustrate the fibre's reinforcement mechanisms during the pull-out process.
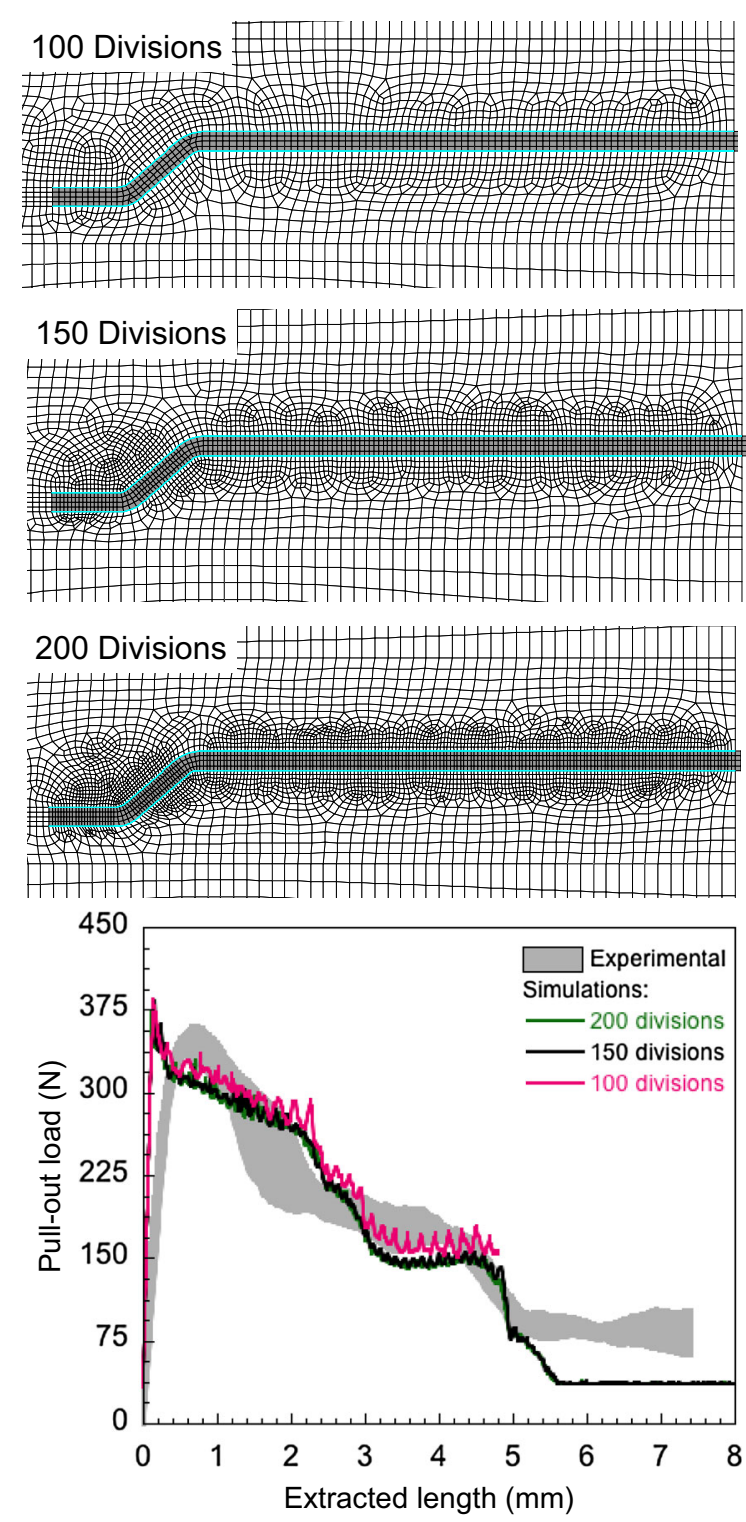

Fig. 8 Three levels of mesh refinement in the fibre longitudinal direction and the corresponding load-extracted length curves contrasted with the experimental ones (shown for a hooked-end fibre inclined at $0^{\circ}$ and loaded at $0.01 \mathrm{~mm} / \mathrm{s}$ )

\subsection{Validation against experimental results}

In order to validate the aforementioned numerical methodology, the numerical pull-out curves are juxtaposed with their experimental counterparts. In particular, the comparison for the pull-out tests at $0.01 \mathrm{~mm} / \mathrm{s}$, $0.1 \mathrm{~mm} / \mathrm{s}$ and $1 \mathrm{~mm} / \mathrm{s}$, with inclination angles of $0^{\circ}$, $30^{\circ}$ and $60^{\circ}$ is given in Figs. 9 and 10 for smooth and 

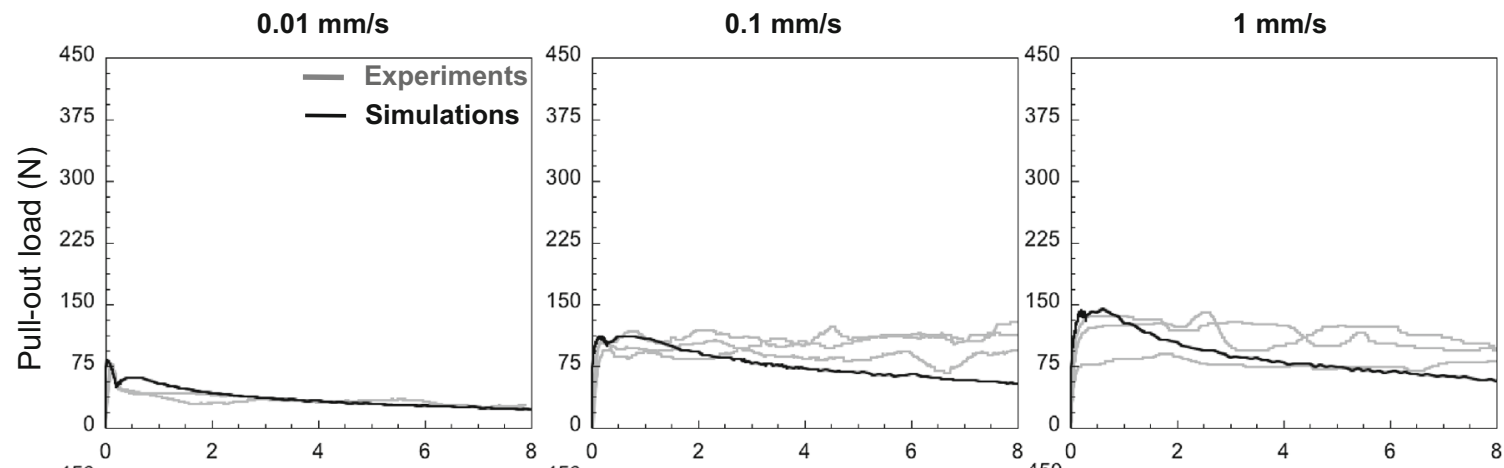

$0^{\circ}$
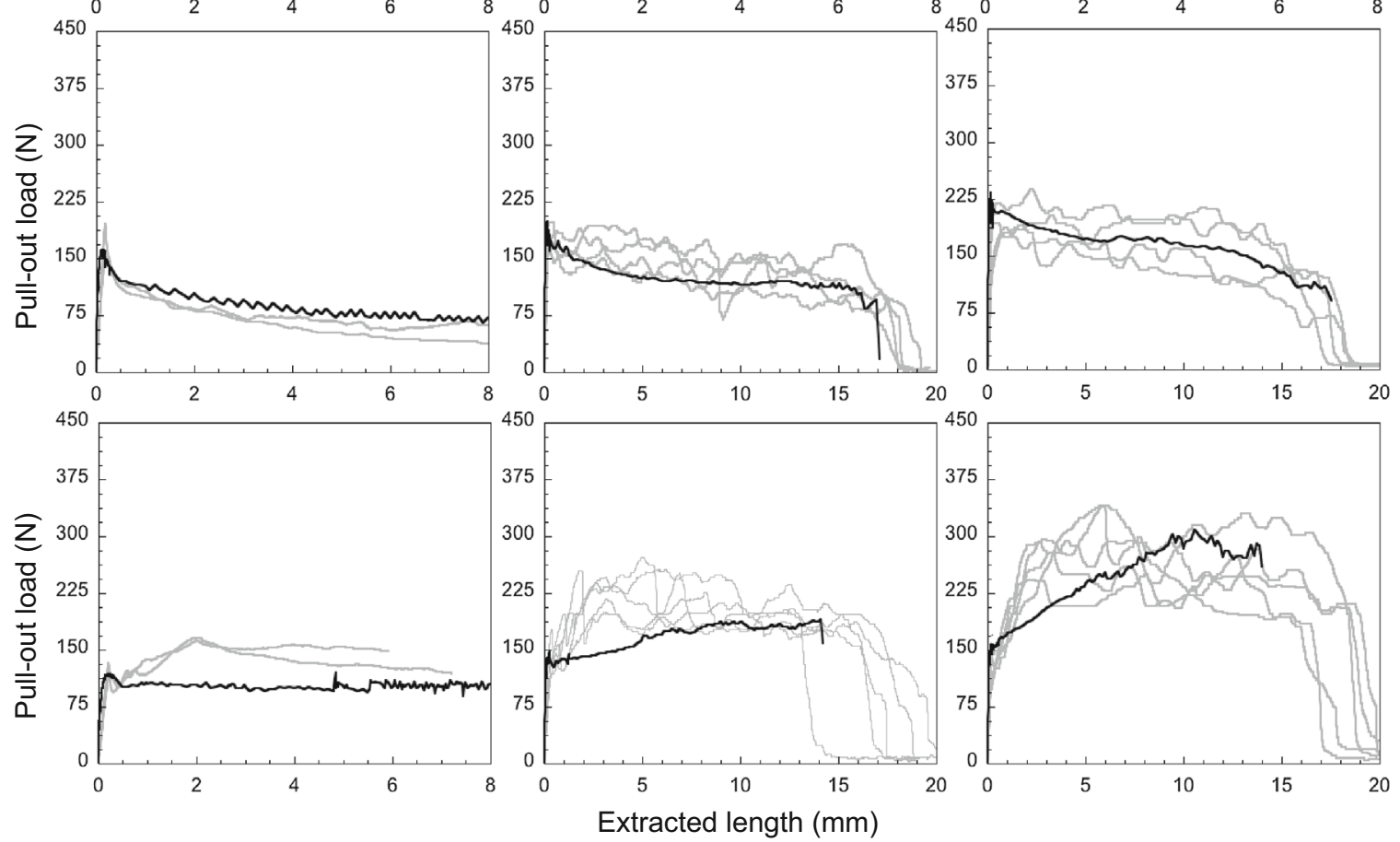

Fig. 9 Numerical-experimental comparison at different displacement rates (columns) and fibre inclinations (rows) for smooth fibres

hooked-end fibres, respectively. In addition, the fibre rupture, which is assumed when the equivalent stress exceeds the steel tensile strength in the case of numerical simulations, is marked with an empty circle (in the series regarding $30^{\circ}$ and $60^{\circ}$ ) in Fig. 10 . It is noteworthy that the global trend, including both the peak loads and the post-peak behaviour are captured remarkably well. Having in mind that the rate effect is taken into consideration solely in the friction law, this is strong evidence that rate-dependent friction is the dominant mechanism behind the observed rate effect in the dynamic pull-out tests.

\subsubsection{Rate sensitivity in the pull-out load}

Experimentally, the smooth fibres are more sensitive to the displacement pull-out rate than the hooked-end ones. Percentage-wise, the increase in the maximum load with the displacement rate is higher in the case of smooth fibres, whereas for the hooked-end cases, this fact is not so relevant due to the preponderance of the hook's reinforcement mechanism. This can be attributed to the mitigation effect of the hooked anchorage, which is in consonance with the results of Tai and El-Tawil (2017).

Table 3 shows the experimental and the numerical (in brackets) first peak load, as well as the percentage 

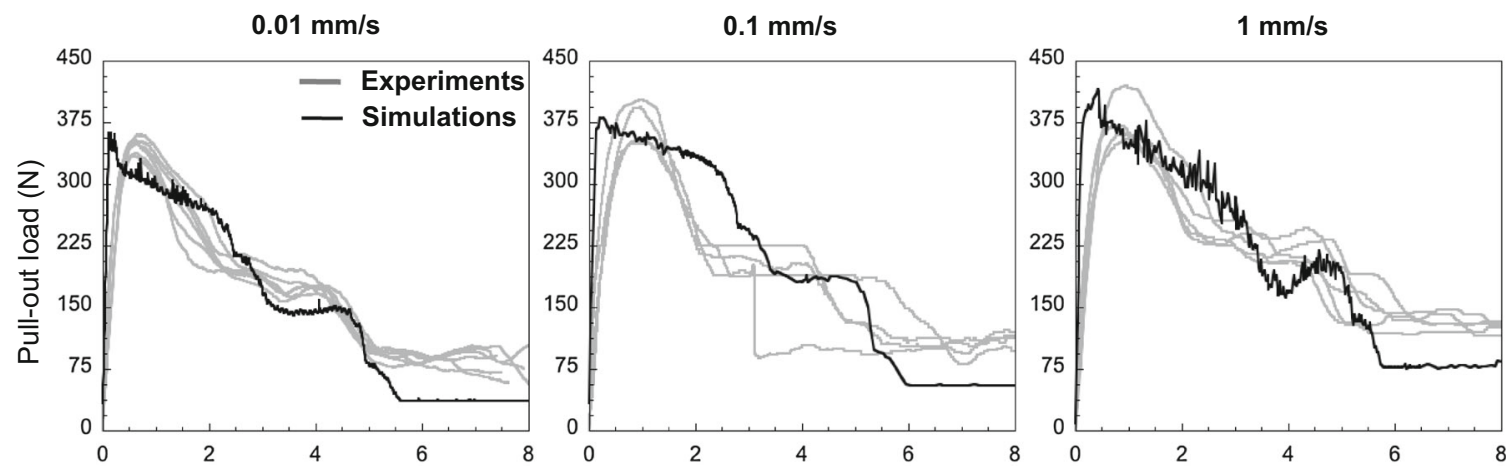

$0^{\circ}$
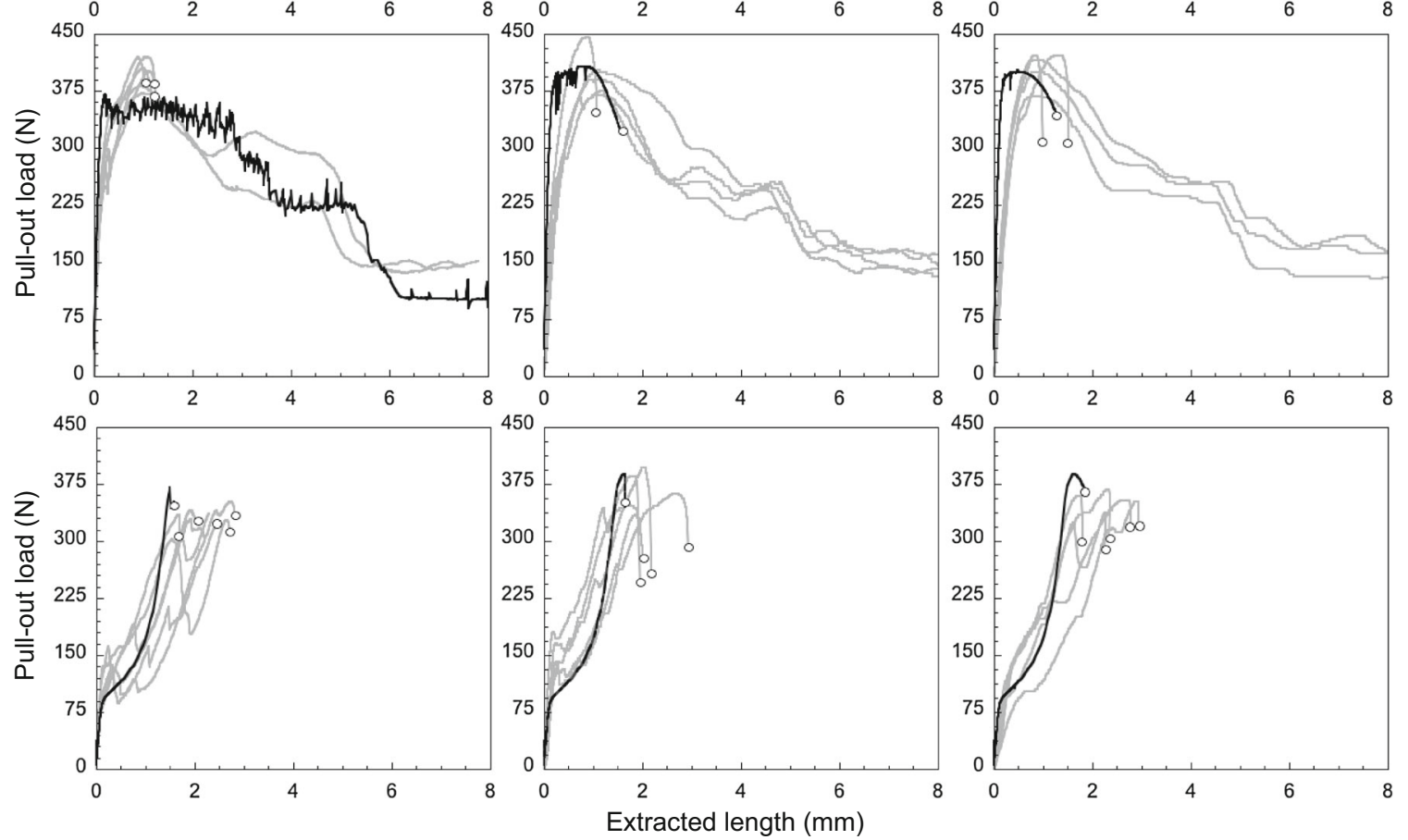

Fig. 10 Numerical-experimental comparison at different displacement rates (columns) and fibre inclinations (rows) for hooked-end fibres, where empty circles represent broken fibres

variation with respect to the previous loading rate. The corresponding extracted length at the first peak loads are given in Table 4. Note that with the same logarithmic increase in the pull-out rate (from 0.01 to $0.1 \mathrm{~mm} / \mathrm{s}$ and from 0.1 to $1 \mathrm{~mm} / \mathrm{s}$ ), less increase is attained in the first peak load for higher loading rates. This indicates a reduced influence of the friction coefficient at higher loading rates.

In Table 4, it can be observed that, for all the displacement rates, numerically and experimentally, the deflection at the peak load increases with the fibre inclination angle. This is due to the fact that fibre exerts more pressure in the concrete matrix as the inclination angle increases, which consequently leads to matrix spalling at the fibre's exit point from the matrix. Moreover, after the matrix spalling, the fibre at this region is easily straightened due to its low flexural stiffness, contributing in this way to increase the length of the stretch of fibre extracted from the matrix at the peak load. The numerical model also captured this phenomenon fairly well.

In addition, from Figs. 9, and 10, one can note that the post-peak load increases with the inclination angle for the pull-out of smooth-fibres. By contrast, this increment is marginal for the pull-out of hookedend fibres. It needs to be pointed that for aligned fibres 
Table 3 Comparison between experimental and numerical (in brackets) first peak load in Newtons for smooth and hooked-end fibres and percentage variation with respect to the previous loading rate

\begin{tabular}{|c|c|c|c|c|c|c|}
\hline \multirow[t]{2}{*}{$v(\mathrm{~mm} / \mathrm{s})$} & \multicolumn{3}{|c|}{ Smooth fibres } & \multicolumn{3}{|c|}{ Hooked-end fibres } \\
\hline & $0^{\circ}$ & $30^{\circ}$ & $60^{\circ}$ & $0^{\circ}$ & $30^{\circ}$ & $60^{\circ}$ \\
\hline 0.01 & $78(82)$ & $173(163)$ & $126(119)$ & $348(351)$ & $380(373)$ & $128(91)$ \\
\hline 0.1 & 104 (109) & 178 (197) & $146(144)$ & $376(380)$ & 396 (399) & $115(94)$ \\
\hline 1 & 117 (138) & $191(227)$ & $127(147)$ & 377 (409) & $401(401)$ & $100(96)$ \\
\hline $100 \Delta P / P$ & 33 (33) & $3(21)$ & $16(21)$ & $8(8)$ & $4(7)$ & $-10(3)$ \\
\hline $100 \Delta P / P$ & $13(27)$ & $7(15)$ & $-13(2)$ & $0(8)$ & $1(1)$ & $-13(2)$ \\
\hline
\end{tabular}

Table 4 Comparison between experimental and numerical (in brackets) extracted length in millimetres at the first peak load for smooth and hooked-end fibres (numerical values in brackets)

\begin{tabular}{|c|c|c|c|c|c|c|}
\hline \multirow[t]{2}{*}{$v(\mathrm{~mm} / \mathrm{s})$} & \multicolumn{3}{|c|}{ Smooth fibres } & \multicolumn{3}{|c|}{ Hooked-end fibres } \\
\hline & $0^{\circ}$ & $30^{\circ}$ & $60^{\circ}$ & $0^{\circ}$ & $30^{\circ}$ & $60^{\circ}$ \\
\hline 0.01 & $0.11(0.03)$ & $0.17(0.14)$ & $0.21(0.19)$ & $0.50(0.21)$ & $0.80(0.22)$ & $0.23(0.14)$ \\
\hline 0.1 & $0.16(0.15)$ & $0.23(0.18)$ & $0.35(0.29)$ & $0.75(0.27)$ & $0.85(0.55)$ & $0.24(0.15)$ \\
\hline 1 & $0.21(0.17)$ & $0.27(0.20)$ & $0.27(0.30)$ & $0.80(0.40)$ & $0.88(0.57)$ & $0.26(0.18)$ \\
\hline
\end{tabular}

$\left(0^{\circ}\right)$ at higher slip rates $(0.1 \mathrm{~mm} / \mathrm{s}$ and $1 \mathrm{~mm} / \mathrm{s})$ for smooth fibres, the numerical pull-out curves exhibit a slight underestimation of the experimental post-peak behaviour. This is due to the fact that the rate sensitivity is considered merely through friction, which is more important for inclined fibres. Indeed this does not occur for hooked-end fibres, since the plastic deformations of the hook induce higher compression hence stronger friction force at the fibre's imprint channel. The contribution of the mechanical anchorage given by the hooked-end fibre after debonding leads to a significant increase in the pull-out load in comparison to the smooth fibres.

Regarding the hooked-end fibres, the simulations properly captured the different load drops during the pull-out tests for the distinct inclinations and displacement rates. They represent the plastic deformation of the hooked-end at both curvatures of the anchorage. As it can be seen, the extracted length and the residual pull-out load in both drops happened at similar values as those of the tests.

\subsubsection{Fibre rupture}

Fibre rupture was observed experimentally for the hooked-end fibre series with $30^{\circ}$ and $60^{\circ}$ inclination angle, see Fig. 10, where empty circles mark the fibres which were broken during pull-out. It is remarkable that the numerical model is capable to capture this occurrence. Indeed, the simulations showed that fibre rupture only occurred for hooked-end fibres at a displacement rate of 0.1 and $1 \mathrm{~mm} / \mathrm{s}$ for the $30^{\circ}$ series and at all the displacement rates for the $60^{\circ}$ series.

\subsubsection{Fibre deformation}

The modelled deformation pattern of the fibre after its full extraction is compared with the real fibre deforma-

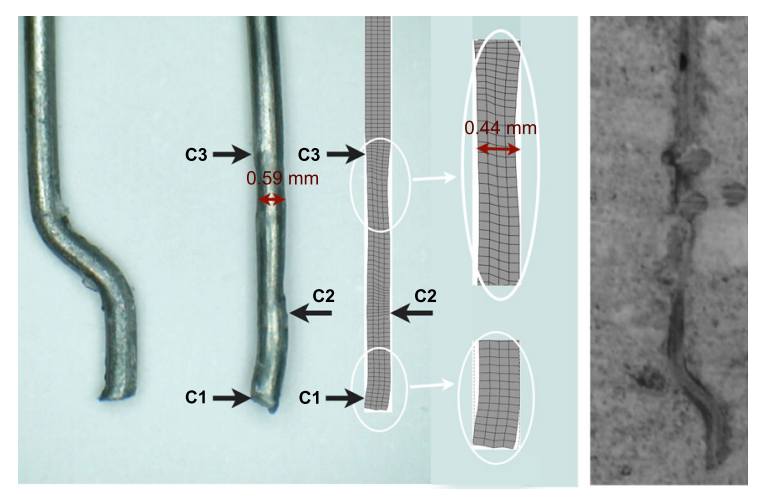

Fig. 11 Experimental-numerical comparison of the hooked-end fibre after the extraction (detail of the hook part) and the observed imprint channel after fibre extraction 
Fig. 12 Four snapshots of Von Mises stress $\left(S_{E Q V}\right)$ distribution and fibre position for a hooked-end fibre (at $0^{\circ}$ of inclination and pull-out rate of $0.01 \mathrm{~mm} / \mathrm{s}$ ) corresponding to the four marked points A, B, C and $\mathrm{D}$ on the load-slip curve
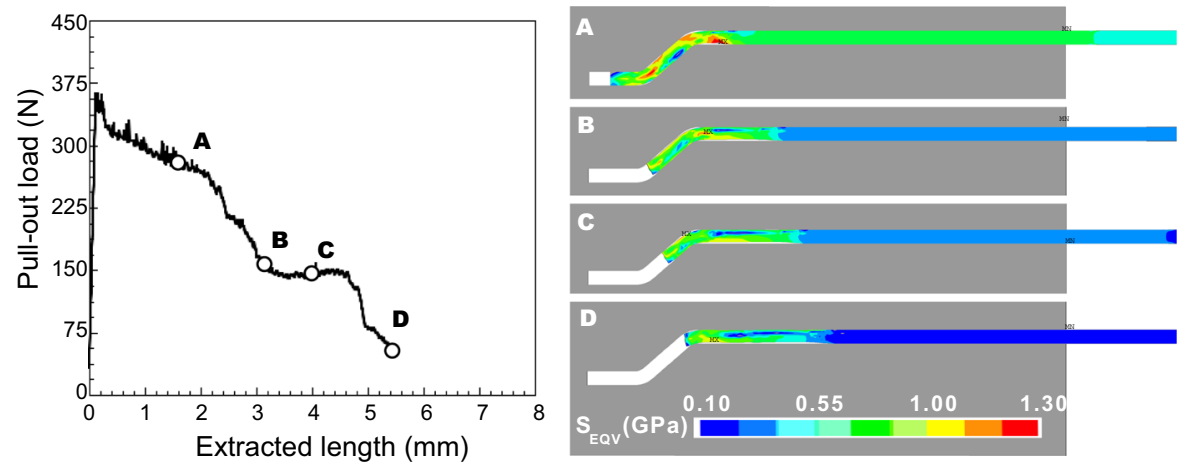

tion in Fig. 11. A VMS-004D-400 USB Microscope camera with a two megapixel resolution was used to assess the deformed fibre shape. Two neckings are observed, as a consequence of the straightening of the two fibre curvatures and the corresponding plastic deformation. This pattern is reproduced in the numerical model. Special attention should be paid to the fibre end, the edge of the fibre is completely deformed both in the experimental and numerical results. Experimentally, the fibre diameter in the necking part is reduced to $0.59 \mathrm{~mm}$ from its original diameter of $0.75 \mathrm{~mm}$. This results a thinning of the fibre cross-section of $21 \%$. By contrast, the modelled fibre height in the necking part is shrunk to $0.44 \mathrm{~mm}$ from the initial $0.556 \mathrm{~mm}$. The corresponding reduction in the fibre cross-section area is $20.9 \%$. The prediction capacity of the proposed numerical model on the fibre necking effect is also remarkable.

Note that the hooked anchorage is not fully straightened either in the experiments or in the numerical simulations. The deformed shape promoted contact at three points along the fibre channel, see points $\mathrm{C} 1, \mathrm{C} 2$ and $\mathrm{C} 3$ in Fig. 11. This is in consonance with the claims of Laranjeira et al. (2010b), who ascertained a threepoint contact mechanism between the hook and the matrix at the end of the pull-out process.

In addition, Fig. 11 shows the experimental fibre channel after fibre extraction. It can be appreciated that the imprint channel that corresponds to the hooked part of the fibre maintains the original shape of fibre hook before being pulled-out. This indicates that no micro spalling had occurred. Indeed, earlier experimental results of Cunha (2010) have shown that no evidence of micro-cracking was detected on the hook's imprint after the fibre pull-out in a high strength matrix.

\subsection{Stress evolution in the fibre}

In order to better understand the fibre pull-out process, four snapshots of the Von Mises stress distribution in the fibre, corresponding to points $\mathrm{A}, \mathrm{B}, \mathrm{C}$ and $\mathrm{D}$ on the load-extracted length $(F-u)$ curve, are depicted in Fig. 12.

The first part of the $F-u$ curve is elastic, followed by a non-linear branch associated with the degradation of the adhesive fibre-matrix bond and some local yielding of the hooked-end. Note that the maximum stresses were attained when the hooked-end was being bent and straightened (point A, Fig. 12). The curved part of the fibre was progressively bent and the interface broken. It bears emphasis that the descending branch of the $F-u$ curve exhibits a deeper drop after passing through each channel curvature (A to B, and C to D). Meanwhile, during the fibre straightening process, see Fig. 12, a plateau $(\mathrm{B}, \mathrm{C})$ forms on the $F$ - $u$ curve. This means that the anchorage effect of the hook was dominant.

The final stage occurs when the hooked-end completely passes both curvature points, the hook is straight-ened and the pull-out process occurs under friction (point $\mathrm{D}$ ) with a descendent tendency due to the reduction of the embedded length of the fibre. Laranjeira et al. (2010b) affirmed that no further plastic deformations take place due to a residual resistance for an incomplete straightening of the hook. Consequently, the fibre slips along the channel with a threepoint contact mechanism. This effect is observed in the numerical simulations and in the deformed shape of the hook geometry shown in Fig. 11. The numerical model corroborated the latter phenomena, which were also observed by other authors such us Markovic (2006), Laranjeira et al. (2010b), Cunha (2010), Abrishambaf et al. (2017). 


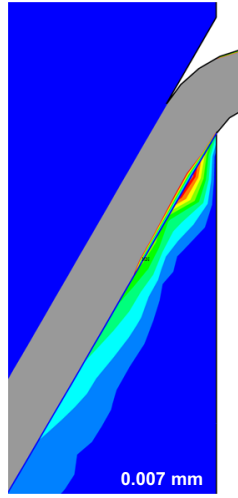

(a)

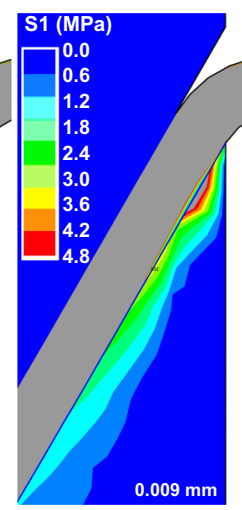

(b) (c)

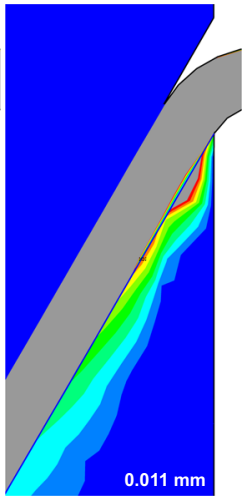

Fig. 13 The first principal stress evolution with respect to the pull-out displacement during the spalling process for hooked-end fibres at slip rate $0.01 \mathrm{~mm} / \mathrm{s}$ with an inclination angle of $60^{\circ}$ (the grey colour represents stresses greater than the tensile strength of the matrix, which is $4.8 \mathrm{MPa}$ )

\subsection{Stress distribution in the matrix}

As mentioned before, in order to save computational effort, the modelling of matrix spalling was simplified as a wedge to be disconnected later on instead of checking the possibilities of cracking in the matrix at each step of loading. However, in order to assure that such a treatment is correct, the stress distribution is checked a posteriori. For instance, the first principal stress distribution in the matrix is demonstrated in Fig. 13 for the case of a hooked-end fibre inclined at $60^{\circ}$ and pulled out with a velocity of $0.01 \mathrm{~mm} / \mathrm{s}$. Note that in Fig. 13a, at the extracted length of $0.007 \mathrm{~mm}$, the tensile strength of the matrix has not been reached. However, in the later steps (extracted length of 0.009 and $0.011 \mathrm{~mm}$ ), the value of the first principal stress in the matrix wedge exceeds the tensile strength, indicated by the grey contour. In the calculations, the corresponding elements were deactivated before the slip reached $0.009 \mathrm{~mm}$ and the matrix wedge would cease to contribute to the overall stiffness.

It needs to be emphasised that matrix fracture does not take place in other zones of the matrix neither for smooth fibres nor for hooked-end ones, see Fig. 14 for the case of 30 and $60^{\circ}$ fibres. The tensile stress distribution has been thoroughly reviewed to ensure this fact. Even for the cases of the hooked-end fibres when fibre rupture occurs, the stresses in the surrounding region of the hook do not exceed the tensile strength. In addition, it is observed from Fig. 14 that the more inclined is

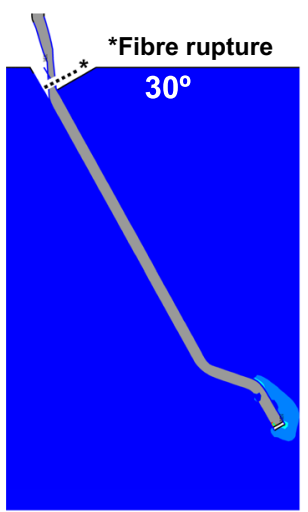

(a)

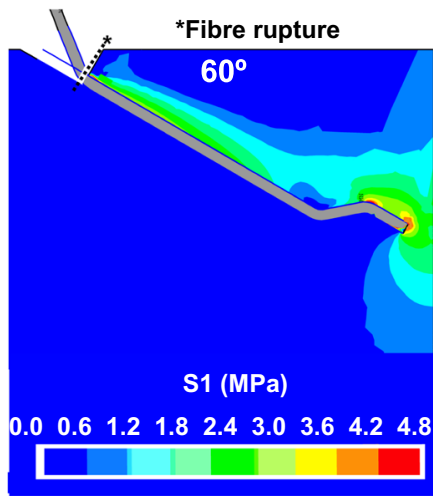

(b)
Fig. 14 The first principal stress distribution in the concrete bulk: a at $30^{\circ}$ and $0.1 \mathrm{~mm} / \mathrm{s} ; \mathbf{b}$ at $60^{\circ}$ and $0.1 \mathrm{~mm} / \mathrm{s}$ during later stages of pull-out (when fibre is either extracted or broken)

the fibre, the higher is the stress level achieved around the hook. Moreover, for the $60^{\circ}$ inclined fibre, greater stresses are more spread around the fibre.

The maximum stress in the matrix is located at the fibre exit point. This is due to the fact that, after tearing the wedge, the fibre presses the remaining edge of the concrete and finally it breaks. It is important to note that although both fibres $\left(30^{\circ}\right.$ and $\left.60^{\circ}\right)$ break, a higher inclination angle leads to a stronger frictional effect, a more severe degradation of the matrix, and thus a larger volume of matrix would be spalled off. This agrees with the study of Zhang and Li (2002) about the effect of inclination angle on fibre rupture load.

Furthermore, it can be seen that fibre rupture at $30^{\circ}$ and $60^{\circ}$ inclination angles occurs at the fibre's exit point from the matrix, as a consequence of the additional stresses due to composed bending loading. This finding is in accordance with Leung and Ybanez (1997) and Laranjeira et al. (2010a), who affirmed that fibre rupture and matrix spalling are common from $30^{\circ}$ onwards.

\section{Conclusions}

A numerical model has been established to simulate the pull-out behaviour of a single inclined steel fibre (both smooth and hooked-end) extracted from a cementitious matrix at different displacement rates. Both the steel fibre and the concrete matrix are depicted as solid elements, whereas the interface in between is modelled with superimposed cohesive elements and contact ele- 
ments to capture the bond-slip behaviour and frictional contact, respectively. In particular, a rate-dependent friction law, widely known in earthquake engineering, has been employed for the first time to capture the rate effect observed in the pull-out tests.

The model was first calibrated with the experimental results for smooth aligned fibres loaded at a quasistatic rate $(0.01 \mathrm{~mm} / \mathrm{s})$. Subsequently, it was validated against a wide range of pull-out tests for smooth and hooked-end fibres at different inclination angles $0^{\circ}, 30^{\circ}$ and $60^{\circ}$ carried out at $0.01,0.1$ and $1 \mathrm{~mm} / \mathrm{s}$. The essential features, such as the global tendency of the loadextracted length curves and the deformed fibre shape at the extracted hooked-end, are reproduced remarkably well. It is particularly noteworthy that the observed rate effect is captured through a rate-dependent friction alone, which is the dominant mechanism behind the dynamic pull-out tests.

The following specific conclusions can be drawn:

- The smooth fibres are more sensitive to the displacement rate than the hooked-end fibres for all the inclination angles.

- The maximum load increases with the inclination angle for the smooth-fibres. By contrast this effect in hooked-end fibres is marginal.

- The mechanical anchorage due to the hooked-end fibre contributes to the significant increase of the pull-out load. Regarding the hooked-end fibres, the simulations properly captured the distinct expected load drops due to the different stages of the hooked end mobilization during the pull out tests for each inclination and rate.

- For hooked-end fibres, the hook part is not fully straightened after extraction. The deformed fibreshape promotes contact at three points along the fibre channel during the extraction of the fibre.

The proposed model allows us to better understand the phenomena involved in the pull-out process, the fibre behaviour within the matrix at different stages, especially in hooked-end fibres, where the mechanisms involved require more attention.

Although SFRC has been dealt with in codes and guidelines, the time-dependent behaviour has not been included yet. This fact needs special attention in structures subjected at different rates than the static ones. The observations provided in this paper may result useful for that purpose. Several factors can affect the timedependent behaviour of smooth and hooked-end fibres, such as, the fibre embedment length, the fibre geometry, the concrete matrix and other ranges of displacement pull-out rates, in other words, further research is still needed in this field.

Acknowledgements Financial support from Ministerio de Ciencia, Innovación y Universidades, Spain, through the projects BIA2015-68678-C2-1-R and RTC-2017-6736-3, is acknowledged. Elisa Poveda appreciates the funding from the International Campus of Excellence CYTEMA, as well as, the University of Castilla-La Mancha, throughout Ayudas para estancias en universidades en el extranjero en 2019 en el ámbito del plan propio de investigación susceptibles de co-financiación por el Fondo FEDER, Programa 010100021 to fund her stay in the University of Minho during 2018 and 2019, respectively. Manuel Tarifa acknowledges the financial support from the Department of Applied Mechanics and Project Engineering, UCLM (2018), and from the Programa propio de $I+D+i$ de la Universidad Politécnica de Madrid para realizar estancias de investigación internacional igual o superior a un mes (2019), with the same purpose. The last two authors acknowledge the support provided by the project ICoSyTec (POCI-01-0145-FEDER-027990) financed by FCT and co-funded by FEDER through the Operational Competitiveness and Internationalization Programme (POCI). The authors thank BEKAERT for the supply of fibres.

\section{References}

Abdallah S, Fan M, Rees D (2018) Bonding mechanisms and strengths of steel fiber reinforced cementitious composites: overview. J Mater Civil Eng 30(3):04018001

Abrishambaf A, Barros JAO, Cunha VMCF, Frazão C (2017) Time dependent behaviour of fibre pull-out in selfcompacting concrete. Cem Concrete Compos 77:14-28

Abu-Lebdeh T, Hamoush S, Heard W, Zornig B (2010) Rate effect on pullout behavior of steel fibers embedded in veryhigh strength concrete. Am J Eng Appl Sci 2:454-466

ACI Committee 544 (2001) State-of-the-art report on fiber reinforced concrete. ACI 1R.544-96 (reapproved 2002). American Concrete Institute, Farmington Hills

Alwan JM, Naaman AE, Guerrero P (1999) Effect of mechanical clamping on the pull-out response of hooked steel fibers embedded in cementitious matrices. Concrete Sci Eng 1:1525

ANSYS (2009) Structural analysis guide-ANSYS user manual-release 12.0. Ansys, Inc., Canonsburg

Banthia N, Trottier JF (1991) Deformed steel fiber cementitious matrix bond under impact. Cem Concrete Res 21(1):158168

Bhutta A, Farooq M, Borges P, Banthia N (2018) Influence of fiber inclination angle on bond-slip behavior of different alkali-activated composites under dynamic and quasi-static loadings. Cem Concrete Res 107:236-246

Bindiganavile V, Banthia N (2005) Impact response of the fibermatrix bond in concrete. Can J Civil Eng 32(5):924-933

Blason S, Poveda E, Ruiz G, Cifuentes H, Fernandez Canteli A (2019) Twofold normalization of the cyclic creep curve of 
plain and steel-fiber reinforced concrete and its application to predict fatigue failure. Int J Fatigue 120:215-227

Cunha VM (2010) Steel fibre reinforced self-compacting concrete (from micro-mechanics to composite behaviour). $\mathrm{PhD}$ thesis. University of Minho

Cunha VMCF, Barros JAO, Sena-Cruz JM (2010) Pullout behaviour of steel fibres in self compacting concrete. ASCE J Mater Civil Construct 22:1-9

Gokoz UN, Naaman AE (1981) Effect of strain-rate on the pullout behaviour of fibres in mortar. Int $\mathrm{J}$ Cem Composit Lightweight Concr 3(3):187-202

Hajsadeghi M, Chin C, Jones S (2018) Development of a generic three-dimensional finite element fibre pullout model. Constr Build Mater 185:354-368

Kim DJ, El-Tawil S, Naaman AE (2008) Loading rate effect on pullout behavior of deformed steel fibers. ACI Mater J 105(6):576-584

Laranjeira F, Aguado A, Molins C (2010a) Predicting the pullout response of inclined straight steel fibers. Mater Struct 43:875-895

Laranjeira F, Molins C, Aguado A (2010b) Predicting the pullout response of inclined hooked steel fibers. Cem Concrete Res 40:1471-1487

Lee Y, Kang S, Kim J (2010) Pullout behavior of inclined steel fiber in an ultra-high strength cementitious matrix. Constr Build Mater 24(10):2030-2041

Leung C, Shapiro N (1999) Optimal steel fiber strength for reinforcement of cementitious materials. J Mater Civil Eng 11:116-123

Leung C, Ybanez N (1997) Pullout of inclined flexible fiber in cementitious composite. J Eng Mech 123(3):239-246

Li V, Wang Y, Backer S (1990) Effect of inclining angle, bundling and surface treatment on synthetic fibre pull-out from a cement matrix. Composites 21(2):132-140

Markovic I (2006) High-performance hybrid-fibre concrete: development and utilisation. PhD thesis, Delft University of Technology, Netherlands

Marone C (1998) The effect of loading rate on static friction and the rate of fault healing during the earthquake cycle. Lett Nat 391:69-72

Naaman AE, Najm H (1991) Bond-slip mechanisms of steel fibers in concrete. ACI Mater J 88:135-145

Nammur G, Naaman AE (1989) Bond stress model for fiber reinforced-concrete based on bond stress-slip relationship. ACI Mater J 86(1):45-57

Nieuwoudt PD, Boshoff WP (2017) Time-dependent pull-out behaviour of hooked-end steel fibres in concrete. Cem Concrete Composit 79:133-147

Nonato Da Silva C, Ciambella J, Barros JAO, Costa I (2019) Analytical bond model for general type of reinforcements of finite embedment length in cracked cement based materials. Int J Solids Struct 167:36-47

Poveda E, Ruiz G, Cifuentes H, Yu R, Zhang XX (2017) Influence of the fiber content on the compressive low-cycle fatigue behavior of self-compacting SFRC. Int J Fatigue 101:9-17
Rabbat B, Russell H (1985) Friction coefficient of steel on concrete or grout. J Struct Eng 111:505

Rice J, Lapuesta N, Ranjith K (2001) Rate and state dependent friction and the stability of sliding between elastically deformable solids. J Mech Phys Solids 49:1865-1898

Ruiz G (2001) Propagation of a cohesive crack crossing a reinforcement layer. Int J Fract 111:265-282

Ruiz G, Elices M, Planas J (1998) Size effect and bond-slip dependence of lightly reinforced concrete beams. Mater Struct 31(10):683-691

Ruiz G, Elices M, Planas J (1999) Minimum reinforcement in concrete members, ESIS IC9, vol 24. Elsevier, New York

Ruiz G, de la Rosa A, Wolf S, Poveda E (2018) Model for the compressive stress-strain relationship of steel fiber-reinforced concrete for non-linear structural analysis. Hormigón Acero 69(S1):75-90

Ruiz G, de la Rosa A, Poveda E (2019) Relationship between residual flexural strength and compression strength in steelfiber reinforced concrete within the new eurocode 2 regulatory framework. Theor Appl Fract Mech 103:102310

Soufeiani L, Raman SN, Jumaat MB, Alengaram UJ, Ghadyani G, Mendis P (2016) Influences of the volume fraction and shape of steel fibers on fiber-reinforced concrete subjected to dynamic loading - a review. Eng Struct 124:405-417

Sujivorakul C, Waas AM, Naaman AE (2000) Pullout response of a smooth fiber with an end anchorage. J Eng Mech 126:986993

Tai YS, El-Tawil S (2017) High loading-rate pullout behavior of inclined deformed steel fibers embedded in ultra-high performance concrete. Constr Build Mater 148:204-218

Tarifa M, Poveda E, Cunha VMCF, Barros JAO (2019) Effect of the displacement rate and inclination angle in steel fiber pullout tests. Int J Fract. https://doi.org/10.1007/ s10704-019-00398-2

Xu M, Hallinan B, Wille K (2016) Effect of loading rates on pullout behavior of high strength steel fibers embedded in ultra-high performance concrete. Cem Concrete Composit 70:98-109

Yu RC, Cifuentes H, Rivero I, Ruiz G, Zhang XX (2016) Dynamic fracture behaviour in fibre-reinforced cementitious composites. J Mech Phys Solids 93:135-152

Zhang H, Yu RC (2016) Inclined fiber pullout from a cementitious matrix: a numerical study. Materials 9:10

Zhang J, Li V (2002) Effect of inclination angle on fiber rupture load in fiber reinforced cementitious composites. Composit Sci Technol 62:775-781

Zhang X, Ruiz G, Tarifa M, Cendón D, Gálvez F, Alhazmi W (2017) Dynamic fracture behavior of steel fiber reinforced self-compacting concretes (sfrsces). Materials 10(11):e1270

Publisher's Note Springer Nature remains neutral with regard to jurisdictional claims in published maps and institutional affiliations. 